\title{
Arid Land Research and Management

\section{Effects of a super absorbent polymer on soil properties and plant growth for use in land reclamation}

Elham Sadat Abrisham, Mohammad Jafari, Ali Tavili, Ahmad Rabii, Mohammad Ali Zare Chahoki, Salman Zare, Todd Egan, Habib Yazdanshenas, Davood Ghasemian \& Mohammad Tahmoures

To cite this article: Elham Sadat Abrisham, Mohammad Jafari, Ali Tavili, Ahmad Rabii, Mohammad Ali Zare Chahoki, Salman Zare, Todd Egan, Habib Yazdanshenas, Davood Ghasemian \& Mohammad Tahmoures (2018) Effects of a super absorbent polymer on soil properties and plant growth for use in land reclamation, Arid Land Research and Management, 32:4, 407-420, DOI: 10.1080/15324982.2018.1506526

To link to this article: https://doi.org/10.1080/15324982.2018.1506526

Published online: 16 Oct 2018.

Submit your article to this journal $\sqsubset$

Џ Article views: 74

View Crossmark data \lceil 


\title{
Effects of a super absorbent polymer on soil properties and plant growth for use in land reclamation
}

\author{
Elham Sadat Abrisham ${ }^{a}$, Mohammad Jafari ${ }^{a}$, Ali Tavili ${ }^{a}$, Ahmad Rabii ${ }^{b}$, \\ Mohammad Ali Zare Chahoki ${ }^{a}$, Salman Zare ${ }^{a}$, Todd Egan ${ }^{c}$, \\ Habib Yazdanshenas ${ }^{a}$ (D), Davood Ghasemian ${ }^{d}$, and Mohammad Tahmoures ${ }^{a}$ \\ ${ }^{a}$ Faculty of Natural Resources, University of Tehran, Tehran, Iran; ${ }^{\mathrm{b}}$ Iran Polymers and Petrochemical \\ Institute, Tehran, Iran; 'Division of Mathematics and Natural Sciences, Elmira College, Elmira, NY, USA; \\ ${ }^{\mathrm{d}}$ Department of Hydrology and Water Resources, University of Arizona, Tucson, AZ, USA
}

\begin{abstract}
Effects of the super absorbent polymer (SAP) were tested on both the soil attributes and growth properties of Seidlitzia rosmarinus in the arid Emrani region of Iran in a reclamation study. A SAP concentration gradient (SAP $0=$ SAP $0 \mathrm{~g} \mathrm{dm}^{-3}$, SAP $1=$ SAP $1 \mathrm{~g} \mathrm{dm}^{-3}$, and SAP $3=$ SAP $3 \mathrm{~g} \mathrm{dm}^{-3}$ of soil) was coupled with 30- and 60-day irrigation intervals, and results were evaluated after two growing seasons. Results indicate that application of SAP 1 increased available water content up to $68.5 \%$ and decreased soil bulk density by $25.5 \%$ and soil infiltration rate by $21.5 \%$. SAP enhanced growth indices and seedling establishment rates of S. rosmarinus under drought stress. In addition, the application of SAP 3 can significantly increased soil cation exchange capacity up to $31 \%$ compared to the control. This study demonstrated the increased water retention properties of SAP that leads to higher soil water storage capacity for S. rosmarinus seedlings during the first months of out-planting in arid regions. Overall, the used SAP enhanced soil and plant properties, but most assessed parameters did not differ between SAPs 1 and 3. Therefore, the $1 \mathrm{~g}$ application rate is recommended based on technical as well as economic considerations.
\end{abstract}

\section{ARTICLE HISTORY}

Received 2 February 2017

Accepted 26 July 2018

\section{KEYWORDS}

Drought stress; Seidlitzia rosmarinus; Soil and plant properties; superabsorbent

\section{Introduction}

Arid and semi-arid regions cover almost one-third of the Earth's surface (Schmidt and Pearson 2016). Although organisms living in these environments have adopted many evolutionary strategies to survive under extreme drought conditions, this thus not guarantee their continuous presence, e.g., in terms of vegetation persistently covering the entire land surface (Mwangi and Dohrn, 2008; Nassef, Anderson, and Hesse 2009). However, human population growth requires more land for agriculture (Tilman et al, 2002; Qiao et al. 2016); thus, methods supporting reclamation of degraded land have become an urgent topic. Regarding this, water-efficient agriculture (Li et al. 2014), as part of a larger water conservation strategy, is the key to sustainable living in arid regions (Shahid et al. 2012; Zhang et al. 2017). 
To meet the growing demand for food and other agro-products, the use of different fertilizers has increased in recent years (Qiao et al. 2016). However, using fertilizers alone cannot solve the problem because water remains the limiting factor for crop growth in arid and semiarid ecosystems. Plant growth in these regions is often subjected to drought stress (Di Castri 1973; Kramer and Boyer 2015; Chen et al. 2016) due to low precipitation and high temperatures (Salinger, Stigter, and Das 2000). As a result, arid land agriculture relies heavily on irrigation for crops to survive. This is, especially, true during the critical period of plant establishment in which soil water content plays the most important role in plant development (Sarah 2006).

It is important to note that soil and water conservation are strongly linked (Wang et al. 2015). Soil erosion is a natural process resulting primarily from water and wind action (Lee et al. 2013) and is highly dependent on soil water content (Ramos and Martínez-Casasnovas 2007). Therefore, to achieve sustainable food production and to reduce soil loss through erosion, different agricultural practices have been adopted in arid and semi-arid regions to increase soil water holding capacity (Chen et al. 2016).

It has been found that the use of superabsorbent acrylate polymers (SAPs) in arid regions improves water use efficiency (Liao et al. 2016). SAPs are a new technology that has been quickly adopted by farmers to maintain soil moisture content (Chen et al. 2016), to reduce soil water loss and increase crop yield ( $\mathrm{Li}$ et al. 2014) in many regions (Wang, Li, and Chen 1998; Chen et al. 2004; Liu et al. 2009; Han et al. 2010; Sharma, Dua, and Malik 2014; Peng et al. 2016).

Incorporation of SAP into soil usually reduces its hydration compared to its water uptake in a beaker with water only (Buchholz and Graham 1998). In fact, SAPs can hold up to 400 times their own weight in water (Huttermann, Zommorodi, and Reise 1999; Arbona et al. 2005; Abedi-Koupai and Asadkazemi 2006; Orikiriza et al. 2009; Chirino, Vilagrosa, and Vallejo 2011). As a result, SAPs are considered suitable to improve agricultural soil (Bouranis Theodoropoulos, and Drossopoulos 1995; Zohuriaan-Mehr and Kabiri 2008; Huttermann, Orikiriza, and Agaba 2009; Sharma, Dua, and Malik 2014; Yang et al. 2014) in order to provide more water for plant roots during water stressed periods as a means to increase plant survival rate and crop yields (Fanta et al. 1971; Johnson 1984; Taylor and Halfacre 1986; Dehgan, Yeager, and F.C.V 1994; Akhter et al. 2004). Along with water storage, SAPs also have the ability to store and release plant nutrients as needed (Bhardwaj et al. 2007); similarly in effect to a slow-release fertilizer (Qiao et al. 2016).

SAPs have been used in different soil textures including sandy loam, loamy soils (Dehgan, Yeager, and F.C.V 1994; Abedi-Koupai and Asadkazemi 2006), and coarse-textured soils (Abedi-Koupai et al. 2008). Thus, in many cases, SAPs can decrease the drought stress for plant growth (Huttermann, Zommorodi, and Reise 1999; Oscroft, Little, and Vireo 2000; Viero, Little, and Oscroft 2000; Viero, Chiswell, and Theron 2002; Arbona et al. 2005; Abedi-Koupai and Asadkazemi 2006; Günes 2007; Orikiriza et al. 2009).

Much effort has been made to produce new versions of SAPs and to study their chemical properties. Further studies have evaluated different SAP types and compositions to determine their potential benefits to soil and crop plants (Yang et al. 2003; Han, Yang, and $\mathrm{Xu}$ 2005; Han et al. 2010). These studies have revealed enhanced effects of different SAP types on crop and soil properties in arid lands (Callaghan, Abdelnour, 
and Lindley 1988; Al-Darby 1996; Chatzoudis and Rigas, 1999; Agaba et al. 2010; Fallahi et al. 2016).

Seidlitzia rosmarinus Bunge ex Boiss. is a perennial woody plant (Breckle 1986; Hedge et al. 1997) and plays an important role in the soil conservation of deserts and dry regions (Koocheki and Mahalati 1994; Jafari et al. 2003). It is used as camel fodder (Koocheki and Mahalati 1994) and was selected for the present study because of its halophytic properties (Kurkova et al. 2002; Hadi, Taheri, and Sharif 2007; Hadi 2009) and previous success in arid land reclamation projects (Kurkova et al. 2002; Moghimi 2005).

As previously mentioned, SAPs have been mainly used for agricultural purposes under greenhouse or field conditions, but there is less information regarding their effectiveness in arid land reclamation with respect to their efficacy on degraded soils or the plants that may grow in these soils. Therefore, based on SAP previous applications in agriculture, and prior use of $S$. rosmarinus in land reclamation, it is hypothesized that using SAP and S. rosmarinus together will be a more efficient method to reclaim land compared to using just one of these factors.

\section{Materials and methods}

\section{Characteristics of planting site}

The planting site was located in Emrani region (Gonabad County, Khorasan Razavi Province, Iran, $\left.34^{\circ} 33^{\prime} 56^{\prime \prime} \mathrm{N}, 58^{\circ} 4^{\prime} 48.8^{\prime \prime} \mathrm{E}\right)$. The region's climate is primarily arid with an annual precipitation of $155 \mathrm{~mm}$ (falling mostly in the winter) and an annual average temperature of $17^{\circ} \mathrm{C}$. The aforementioned conditions demonstrate a lack of sufficient water for plants during the growing season. Soil texture of this area is categorized as a sandy loam that has been subjected to wind erosion.

\section{Soil analysis}

Prior to out-planting, soil sampling was performed in the planting pits and some of the soil properties were determined (Table 1).

\section{Plant material}

S. rosmarinus Bunge ex Boiss. (Amaranthaceae) 4-month-old seedlings were provided by the Department of Natural Resources Office in Gonabad and were approximately $10 \mathrm{~cm}$ tall when planted in mid-February.

Table1. A summary of the some physical and chemical properties of the soil in Emrani region.

\begin{tabular}{lr}
\hline Soil properties & Amount \\
\hline Soil texture & Sandy loam \\
Clay (\%) & $16.82 \pm 2.82$ \\
Silt (\%) & $15.57 \pm 2.96$ \\
Sand (\%) & $67.62 \pm 2.82$ \\
Bulk density $\left(\mathrm{g} / \mathrm{cm}^{3}\right)$ & $1.58 \pm 0.07$ \\
(EC) $\left(\mathrm{dS} \mathrm{m}^{-1}\right)($ saturation extract) & $0.4 \pm 0.08$ \\
pH & $8.3 \pm 0.21$ \\
Organic matter (\%) & $0.4 \pm 0.05$ \\
CEC (meq/100gr) & $6.4 \pm 1.42$ \\
K (ppm) & $197.69 \pm 47.41$ \\
P (ppm) & $25.49 \pm 2.50$ \\
$\mathrm{~N}(\%)$ & $0.2 \pm 0.01$ \\
\hline
\end{tabular}




\section{Super absorbent polymer}

The SAP Stockosorb ${ }_{500}{ }^{\circledR}$ (Evonik Creavis $\mathrm{GmbH}$, Marl, Germany) was used as the soil amendment. This SAP (hydrogel) is an acrylamide/acrylic acid copolymer potassium salt, which has the ability to absorb a high volume of water due to a network of spaces created by its cross-linked structure (Table 2).

\section{Soil amendment levels, S. rosmarinus planting and watering treatments}

The experimental design consisted of three concentrations of SAP mixed into the soil, and each of these three SAP concentrations received two levels of watering. This was replicated four times, in which there were four holes per replicate, for a total number of 96 holes. Plots were laid-out in a straight line, and holes, $50 \mathrm{~cm}$ deep with a $50 \mathrm{~cm}$ diameter, were dug $3 \mathrm{~m}$ apart.

SAP was mixed with the backfill soil of each treated plant according to manufacturer's recommendation. Stockosorb ${ }_{500}{ }^{\circledR}$ concentrations were 0 (control), 1 , and $3 \mathrm{~g} / \mathrm{dm}^{3}$ soil (SAP $0=$ SAP $0 \mathrm{~g} \mathrm{dm}^{-3}$, SAP $1=\mathrm{SAP} 1 \mathrm{~g} \mathrm{dm}^{-3}$, and SAP $3=\mathrm{SAP} 3 \mathrm{~g} \mathrm{dm}^{-3}$ of soil). SAPs 1 and 3 were mixed with 6.4 and $19.2 \mathrm{~L}$ water, respectively, so that after $45 \mathrm{~min}$, SAPs were saturated completely and ready to mix with soil. Chosen concentrations and the mixing procedures were determined based on prior studies (Arbona et al. 2005; Agaba et al. 2010; Chirino, Vilagrosa, and Vallejo 2011). The average volume of soil for each hole was approximately $0.064 \mathrm{~m}^{3}$; therefore, different levels of 0,64 , and $192 \mathrm{~g}$ SAPs were applied within planting holes to maintain a consistent treatment of 0 , 1 , and $3 \mathrm{~g} / \mathrm{dm}^{3}$ soil. In this study, the amount of SAP was calculated per hole, so in the field, it was possible to calculate the required amount of SAP based on the number of holes per hectare.

Hole preparation via the addition of SAP was accomplished in early February 2012, and S. rosmarinus seedlings were out-planted in mid-February 2012, with the beginning of the winter rainy season. Seedlings were 4 months old with an average shoot height of $10 \mathrm{~cm}$.

Plants were watered via mobile tanker using well water from the Department of Natural Resources office in Gonabad. The timing and amount of watering were accomplished based on Natural Resources projects. Soil was completely (fully) rehydrated six times at 30-day intervals (what is usual in Natural Resources projects), or partially rehydrated three times at 60-day intervals (to test the efficiency of SAP). Irrigation event delivered $152 \mathrm{~mm}$ (equal of $30 \mathrm{~L}$ ) of water for each seedling for each time of watering. Plants were harvested in late May of 2013 after about 15 months of growth.

Table 2. Some properties of Stockosorb ${ }_{500}$.

\begin{tabular}{lc}
\hline Basis & Crosslinked acrylamide/acrylic acid copolymer partially potassium neutralized $^{\mathrm{a}}$ \\
\hline Particle size distribution $(\mathrm{mm})$ & 500 Medium: $0.8-2.0$ \\
& 500 Micro: $0.2-0.8$ \\
& 500 Powder: $<0.2^{\mathrm{a}}$ \\
Bulk density $(\mathrm{g} / \mathrm{L})$ & 500 Medium: $620 \pm 40$ \\
& 500 Micro: $620 \pm 40$ \\
& 500 Powder: $600 \pm 20^{\mathrm{a}}$ \\
pH-value $\left(1 \mathrm{~g} / \mathrm{L} \mathrm{H}_{2} \mathrm{O}\right)$ & $7.0-7.8$ \\
Solubility & Insoluble in water and organic solutions; swells to gel upon contact with aqueous \\
& solutions (swelling ratio ranging between 150 and 400$)$ \\
\hline
\end{tabular}

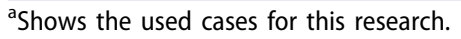




\section{The measured properties of soil and plant}

The soil texture was a sandy loam, and properties including $\mathrm{pH}$ ( $\mathrm{pH}$ meter), EC (EC meter), Cation Exchange Capacity (ammonium acetate method), organic matter (Walkley-Black titration method), soil infiltration rate (double ring method $-7 \mathrm{~cm} \cdot \mathrm{h}^{-1}$ for control $=0$ ), bulk density (core method), and plant available water (pressure plate device) were determined from soil samples taken from a depth of 0-30 cm.

Plant shoot height (via ruler) and basal diameter (via calipers) were determined at planting (mid-February) and ending (late May 2013) times on freshly picked plants. The difference between the two measurements was used to determine the different SAP level's effect on height and basal diameter performance of the plant. Final fresh weight biomass and plant establishment percentage based on the number of surviving individuals was calculated at the end of the experiment.

\section{Statistical analysis}

Data were analyzed using $a \times b$ factorial ANOVA at the $\alpha=0.05$ level. When significant differences were found, a Duncan's New Multiple Range Test was used to determine significant treatments among experimental groups. All statistical analyses were performed using SPSS16.0 for Windows.

\section{Results}

\section{Effects of SAP on soil characteristics}

None of the SAP treatments affected $\mathrm{pH}$, EC, or organic matter significantly, whereas other soil properties were affected by SAP levels.

\section{Cation exchange capacity}

Soil cation exchange capacity (CEC) increased significantly with an increase in SAP content (Figure 1). Maximum CEC increase was observed in the SAP 3 treatment which increased CEC up to $31 \%$ compared to the control.

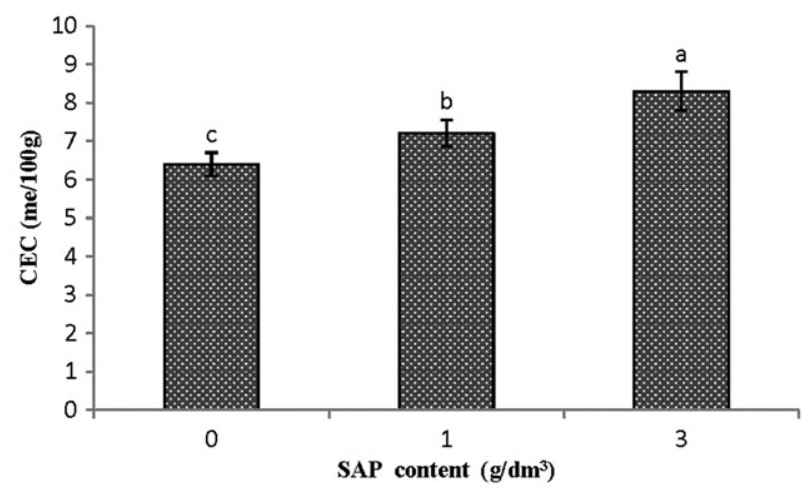

Figure 1. Main effect of SAP application level on soil cation exchange capacity. Bars with different letters indicate significant differences at $p<0.05$ (number of observations: 8 ). 


\section{Bulk density}

Main factors that determine soil bulk density include soil organic matter, soil texture, and the density of soil minerals. Bulk density significantly decreased with an increase in SAP content (Figure 2). The minimum soil bulk density was found at the SAP 3 treatment $\left(1.45 \mathrm{~g} / \mathrm{cm}^{3}\right)$, whereas the largest measured bulk density was found for the SAP 0 $\left(1.56 \mathrm{~g} / \mathrm{cm}^{3}\right)$.

\section{Plant available water content}

Plant available water content significantly increased with increasing SAP content (Figure 3), and therefore the maximum increase in plant available water was found at the SAP 3 treatment with a $143 \%$ increase compared to the SAP 0 . In addition, this same treatment was the most effective at holding soil water holding over time.

\section{Soil infiltration rate}

Soil infiltration rate significantly decreased with increasing SAP concentration (Figure 4). The minimum soil infiltration rate was found at the SAP 3 treatment with a $37 \%$ decrease compared to the SAP 0 (control).

\section{Effects of SAP on plant indices}

SAP did have a significant effect on shoot fresh weight biomass and plant establishment percentage, whereas there were no significantly different changes in the basal diameter at any concentration tested.

\section{Plant establishment percentage}

Analysis of variance demonstrated a significant difference for some, but not all, SAP concentrations for plant establishment. Plant establishment percentage for treatments

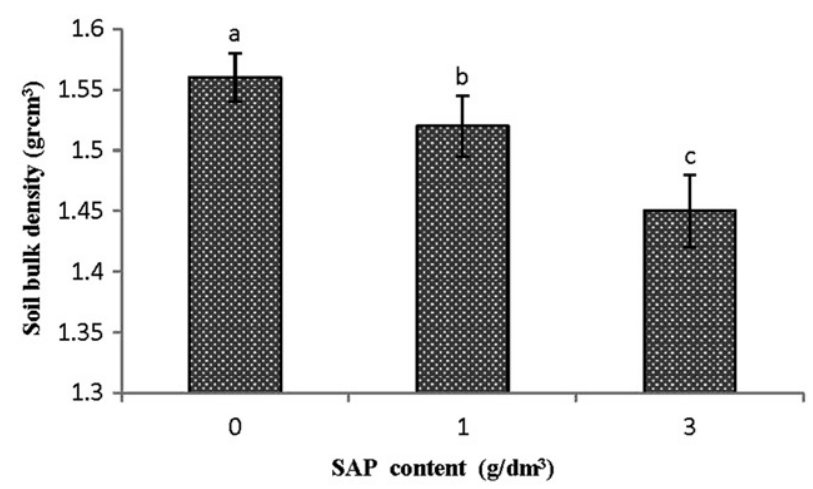

Figure 2. Main effect of SAP application level on soil bulk density in relation to an SAP gradient. Bars with different letters indicate significant differences at $p<0.05$ (number of observations: 8). 


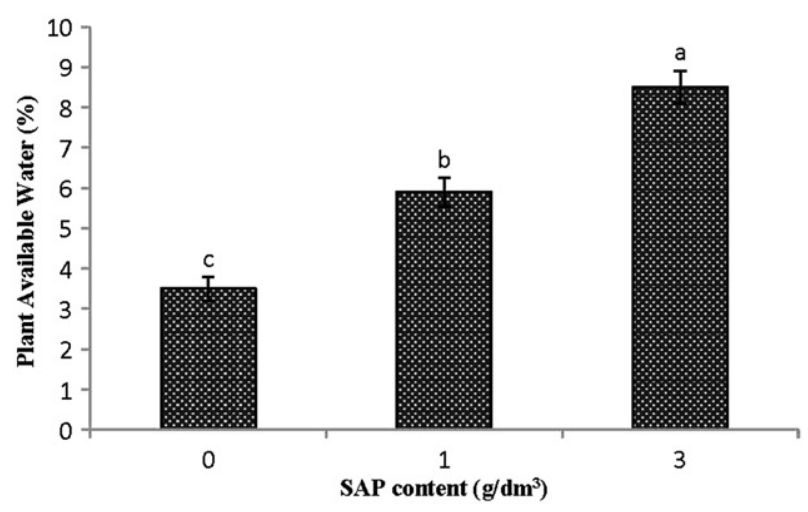

Figure 3. Main effect of SAP concentration on plant available water. Bars with different letters indicate denote significant differences at $p<0.05$ (number of observations: 8 ).

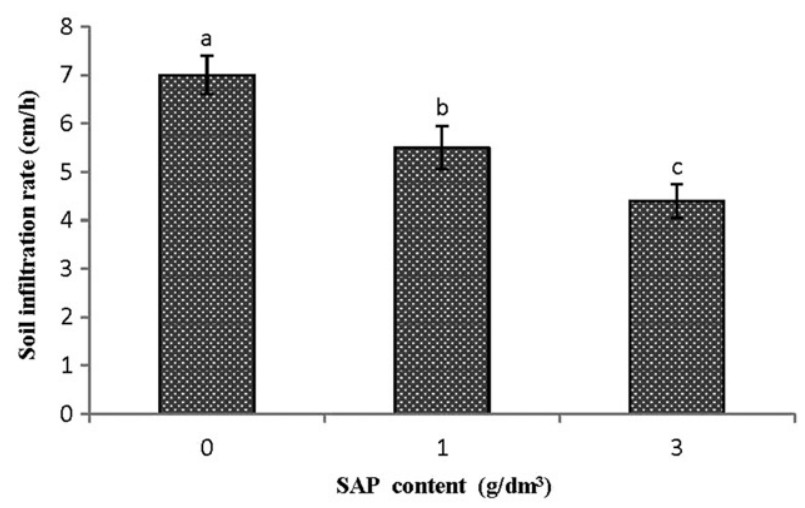

Figure 4. Main effect of SAP level on soil infiltration rate in relation to different SAP content concentrations in the soil. Bars with different letters indicate significant differences at $p<0.05$ (number of observations: 8).

containing SAPs 1 and 3 with both limited and complete irrigations demonstrated no significant changes compared to complete irrigation in the SAP 0. In the control (SAP 0) treatment, complete irrigation level caused a significant and considerable increase in establishment percentage. For limited irrigation, percent of seedling establishment was almost 2.5 times greater in soils containing SAP compared to the control. For SAPs 0, 1 , and 3, seedling establishment percentage was $29 \%, 69 \%$, and $70 \%$, respectively, in limited irrigation condition. While for SAPs 0 , 1, and 3, seedling establishment percentage was about $70 \%$ in complete irrigation condition (Figure 5).

\section{Plant shoot height}

Plant shoot height in treatments containing SAPs 1 and 3 demonstrated no significant differences compared to the control with complete irrigation (Figure 6). Plant shoot height for plants receiving the complete water treatment demonstrated less variation between the SAP treated soils and the control. With limited irrigation, however, mean S. rosmarinus height was greater in the SAP groups compared to the control (Figure 6). 


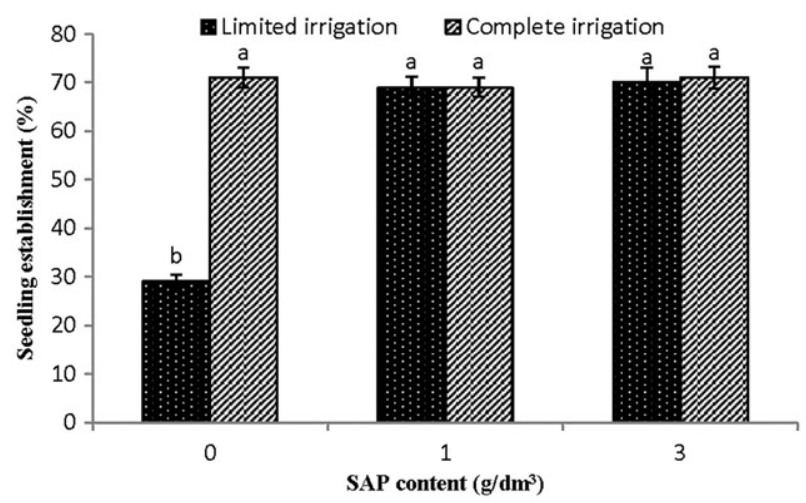

Figure 5. Effect of two SAP levels and different watering intervals on seedling establishment percentage. Limited and Complete irrigation occurred once every 30 and 60 days, respectively (number of observations: 4). (The last date of observation: 25/05/2013).

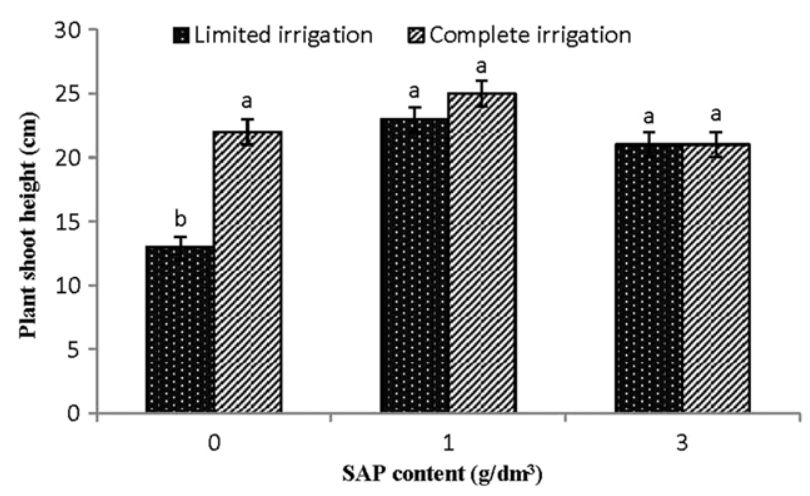

Figure 6. Effect of SAP levels and different watering intervals on Plant shoot height. Values represent the mean of replicates and different letters indicate significant differences at $p<0.05$. (The last date of observation: 25/05/2013).

Despite a lack of significant differences among treatments, it is important to note that the SAP 1 treatment increased plant shoot height similarly to that of the control under limited irrigation.

\section{Shoot fresh weight biomass}

Shoot fresh weight of S. rosmarinus biomass was significantly affected by treatment type. The SAP 3 treatment had the highest aboveground biomass in both the limited $(115 \mathrm{~g})$ and complete $(125 \mathrm{~g})$ irrigation treatments. Although no significant differences were observed between SAPs 1 and 3, there were significant differences between the treated and control groups receiving limited irrigation (63 g) (Figure 7).

\section{Discussion}

Using water-conserving methods and enhancing water efficiency in arid and semi-arid regions is critical to plant establishment. An important irrigation management decision 


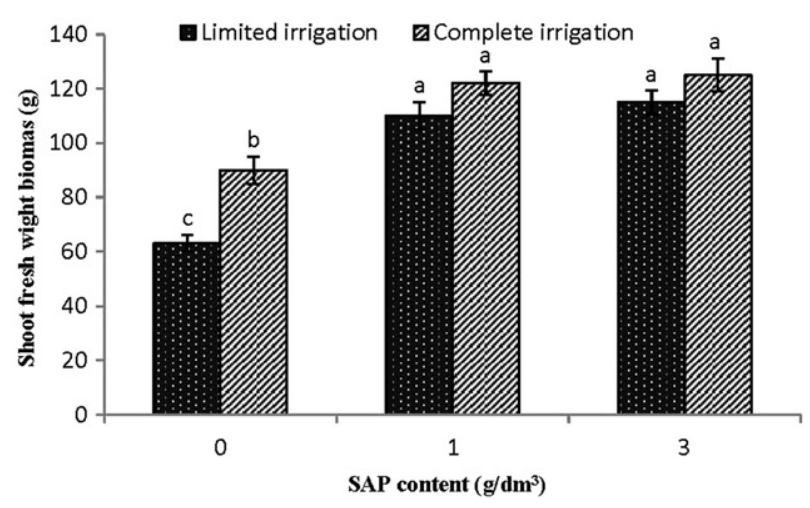

Figure 7. Effect of SAP level and different watering intervals on the shoot fresh biomass. Values represent the mean of replicates, and different letters indicate significant differences at $p<0.05$. (The last date of observation: 25/05/2013).

is to select proper irrigation frequency (Devitt, Bowman, and Morris 1991), so employing new techniques such as SAPs can be part of that decision. SAPs, along with proper irrigation intervals, can help maintain and slowly-release water and nutrients into the soil during periods of stress. This is because SAPs can swell to absorb up to 400 times their own weight in water (Orikiriza et al. 2009; Chirino, Vilagrosa, and Vallejo 2011). When irrigation is completed or raining has ended, SAPs act as reservoirs and water is released slowly into the root environment. In this way, water release is gradual, thus prolonging soil moisture availability (Jafari et al. 2018).

This present study indicates that besides having a positive effect on soil water availability, SAPs can also have a minimizing effect on some physicochemical properties of soil that would otherwise negatively affect plant growth. Results demonstrated that soil CEC in treatments containing $0.05 \mathrm{wt} \%$ and $0.1 \mathrm{wt} \%$ of SAP is significantly higher than in the control samples. CEC is one of the most important characteristics of the soil, and it increases the ability of the soil to retain cations and exchange them with plants (Jafari and Sarmadian 2003). SAPs can affect the exchange environment in soil (Chen et al. 2004), which is more pronounced in arid regions (Tavili et al. 2010).

The findings of this research showed various effects of the SAP on different properties related to soil moisture. Results demonstrated that plant available water is increased to $68 \%$ and $143 \%$, in treatments containing SAPs 1 and 3, respectively because SAPs can absorb and hold water up to 400 times their own weight (Huttermann, Zommorodi, and Reise 1999; Orikiriza et al. 2009). Li et al. (2014) found that using SAPs could improve soil water-holding capacity, leading to a larger amount of water in the plant rooting environment.

Soil infiltration rate also decreased in treatments containing SAPs 1 and 3 by $21.5 \%$ and 37\%, respectively, and these findings concur with Chirino, Vilagrosa, and Vallejo (2011). It appears that SAPs hold a large amount of water and slowly release it into the soil environment causing a decrease in infiltration rate. Other studies indicated that using SAPs decreases the hydraulic conductivity of soil (Bhardwaj et al. 2007; Agaba 2007). This may be because soils containing SAPs can absorb more water and release that absorbed water gradually as the soil moisture content decreases (Al-Darby 1996; 
Bakass, Mokhlisse, and Lallemant 2002; El-Rehim, Hegazy, and El-Mohdy 2004; Ni et al. 2010; Chen et al. 2016).

Results demonstrated that using SAP 1 would greatly enhance the drought tolerance of plants and minimize the effect of drought on establishment percentage, plant shoot height, and aboveground biomass (Figures 5-7). In the case of limited irrigation, these properties were equal to those of complete irrigation, or only slightly less, when SAPs were used. Viero, Chiswell, and Theron (2002) demonstrated that using hydrogels in a sandy clay loam soil has positive impacts on both transplant survival and growth of Eucalyptus grandis W. Hill in Zululand, and these results were further supported by Callaghan et al. (1989) and Chirino, Vilagrosa, and Vallejo (2011). Such improvements could be attributed to increased water storage and slow release of water based on a plant's need. SAPs help to save water by reducing water infiltration rate and evaporation and also by increasing the duration of water retention in the soil, which could improve the survival and plant quality during droughts (Bakass, Mokhlisse, and Lallemant 2002; Abedi-Koupai et al. 2008). Water is vital for plant survival and growth because of its role in absorbing nutrients from the soil and dehydrolizing various chemical compounds within the plant.

In addition, a positive effect on $S$. rosmarinus shoot biomass was observed using SAP treatments. Water deficit caused a reduction in the rate of leaf initiation (Clough and Milthorpe 1975) and leaf expansion (Watts 1974), which in turn lead to a smaller leaf area and decreased assimilatory surface resulting in a lower shoot biomass and yield. SAP application helped the plant to overcome water deficit condition and produce more leaves and green tissues. Kumar (2015) demonstrated that using SAPs could significantly increase maize yield by enhancing soil physical properties and water productivity in arid lands. Another study reported an overall enhancement of plant growth and quality when a hydrogel was added to the growth media (Montesano et al. 2015). Liu et al. (2009) indicted that SAP addition with fertilizer increased dry matter along with increased seedling emergence time of Pinus pinaster William Aiton.

This study demonstrated that SAP decreases the need for irrigation and artificial irrigation while increasing the effectiveness of low natural precipitation as a vital factor in arid and semi-arid regions, and it is consistent with the results of Abedi-Koupai et al. (2008). By increasing SAP content, CEC and plant available water significantly increased, but bulk density and soil infiltration rates significantly decreased. However, no significant difference was observed between the SAPs 1 and 3 in establishment percentages, plant shoot height, and above ground biomass in S. rosmarinus (Figures 5-7). This may be because of the water utilization efficiency of this succulent halophyte. Shahid et al. (2012) demonstrated that moisture retention and soil porosity were greatly increased with SAP application. Hydrogels are most effective in coarse-textured soils. Al-Humaid and Moftah (2007) found that by adding $0.4-0.6 \%$ of the hydrophilic polymer "Stockosorb K-400" to the soil could enhance Conocarpus erectus L. seedling drought tolerance in arid and semi-arid regions.

\section{Conclusion}

Using the SAP Stockosorb ${ }^{\circledR}$ as a soil amendment in sandy loam arid soil can considerably enhance water uptake and utilization for plant growth and soil conservation purposes. In 
other words, this study demonstrated the water retention effectiveness of Stockosorb ${ }^{\circledR}$ leading to higher soil water storage under field conditions of land reclamation.

Because there were no significant differences for any parameters measured between the SAPs 1 and 3 with limited irrigation, the SAP 1 is recommended based on technical and economic considerations. The lower concentration was selected because it was the most affordable choice to improve soil moisture conditions, increase available water content, and decrease soil bulk density and soil infiltration rate in the sandy loam soils of the Emrani region. Required SAP amendments can be calculated for any arid region based on the size and number of holes. Further studies should be completed to determine the number of different factors affecting the long-term, the effectiveness of SAPs, the effect of SAPs on soil organisms, as well as additional soil/plant interactions in arid and semi-arid regions.

\section{Acknowledgments}

The authors thank the Department of Natural Resources Office in Gonabad for donating the $S$. rosmarinus seedlings as well as the water to continue this study.

\section{Funding}

The authors thank the Iranian National Science Foundation for their generous financial support (Grant No: 89003312).

\section{ORCID}

Habib Yazdanshenas (D) http://orcid.org/0000-0003-1460-6575

\section{References}

Abedi-Koupai, J., S. S. Eslamian, and J. Asad Kazemi. 2008. Enhancing the available water content in unsaturated soil zone sing hydrogel, to improve plant growth indices. Ecohydrology \& Hydrobiology 8(1):67-75.

Abedi-Koupai, J., and J. Asadkazemi. 2006. Effects of a hydrophilic polymer on the field performance of an ornamental plant (Cupressus arizonica) under reduced irrigation regimes. Iranian Polymer Journal 15:715-25.

Agaba, H., L. J. Baguma Orikiriza, O. Esegu, J. Francis, J. Obua, J. D. Kabasa, and A. Huttermann. 2010. Effects of hydrogel amendment to different soils on plant available water and survival of trees under drought conditions. Clean - Soil, Air, Water 38(4):328-35.

Akhter, J., K. Mahmood, kM. Malik, A. Mardan, M. Ahmad, and M. M. Iqbal. 2004. Effects of hydrogel amendment on water storage of sandy loam and loam soils and seedlings growth of barley, wheat and chickpea. Plant, Soil and Environment 50:463-9.

Al-Darby, A. 1996. The hydraulic properties of a sandy soil treated with gel-forming soil conditioner. Soil Technology 9(1-2):15-28.

Al-Humaid, A. I., and A. E. Moftah. 2007. Effects of hydrophilic polymer on the survival of buttonwood seedlings grown under drought stress. Journal of Plant Nutrition 30(1):53-66.

Arbona, V., D. J. Iglesias, J. Jacas, E. Primo-Millo, M. Talon, and A. Gómez-Cadenas. 2005. Hydrogel substrate amendment alleviates drought effects on young citrus plants. Plant and Soil 270(1):73-82.

Bakass, M., A. Mokhlisse, and M. Lallemant. 2002. Absorption and desorption of liquid water by a super absorbent polymer: Effect of polymer in the drying of the soil and the quality of certain plants. Journal of Applied Polymer Science 83(2):234-43. 
Bhardwaj, A. K., I. Shainberg, D. Goldstein, D. Warrington, and G. Levy. 2007. Water retention and hydraulic conductivity of cross-linked poly acryl amides in sandy soils. Soil Science Society of America Journal 71(2):406-12.

Bouranis, D. L., A. G. Theodoropoulos, and J. B. Drossopoulos. 1995. Designing synthetic polymers as soil conditioners. Communication of Soil Science and Plant Analysis 26(9-10):1455-80.

Breckle, S. W. 1986. Studies of halophytes from Iran and Afghanistan. Proceedings of the Royal Society of Edinburgh. Section B. Biological Sciences 89:203-15.

Buchholz, F. L., and A. T. Graham. 1998. Modern superabsorbent polymer technology, 279. New York, NY: JohnWiley \& Sons, Inc.

Callaghan, T. V., H. Abdelnour, and D. K. Lindley. 1988. The environmental crisis in the Sudan: The effect of water absorbing synthetic polymers on tree germination and early survival. Journal of Arid Environments 14:301-17.

Callaghan, T. V., D. K. Lindley, O. M. Ali, H. A. E. Nour, and P. J. Bacon. 1989. The effect of water-absorbing synthetic polymers on the stomata conductance, growth and survival of transplanted Eucalyptus microtheca seedlings in the Sudan. Journal of Applied Ecology 26(2):663-72.

Chatzoudis, G. K., and F. Rigas. 1999. Soil salts reduce hydration of polymeric gels and affect moisture characteristics of soil. Communications in Soil Science and Plant Analysis 30(17-18):2465-74.

Chen, P., W. A. Zhang, W. Luo, and Y. E. Fang. 2004. Synthesis of super absorbent polymers by irradiation and their applications in agriculture. Journal of Applied Polymer Science 93(4):1748-55.

Chen, X., X. Mao, Q. Lu, Z. Liao, and Z. He. 2016. Characteristics and mechanisms of acrylate polymer damage to maize seedlings. Ecotoxicology and Environmental Safety 129:228-34.

Chirino, E., A. Vilagrosa, and V. R. Vallejo. 2011. Using hydrogel and clay to improve the water status of seedlings for dry land restoration. Plant and Soil 344(1-2):99-110.

Clough, B. F., and F. L. Milthorpe. 1975. Effects of water deficits on leaf development in tobacco. Australian Journal of Plant Physiology 2(3):291-300.

Dehgan, B., T. H. Yeager, and A. F.C.V. 1994. Pholinia and podocarpus growth response to a hydrophilic polymer amended medium. Horticultural Science 29(6):641-4.

Devitt, D. A., D. C. Bowman, and R. L. Morris. 1991. Effects of irrigation frequency, salinity of irrigation water, and soil type on growth and response of bermudagrass. Arid Land Research and Management 5(1):35-46.

Di Castri, F. 1973. Climatographical comparisons between Chile and the western coast of North America. In Mediterranean type ecosystems, eds. F. Di Castri and H. A. Mooney, 21-36. Berlin: Springer.

El-Rehim, H. A., E. S. A. Hegazy, and H. L. El-Mohdy. 2004. Radiation synthesis of hydrogels to enhance sandy soils water retention and increase plant performance. Journal of Applied Polymer Science 93(3):1360-71.

Fallahi, H. R., G. Zamani, M. Mehrabani, M. Aghhavani-Shajari, and A. Samadzadeh. 2016. Influence of superabsorbent polymer rates on growth of saffron replacement corms. Journal of Crop Science and Biotechnology 19(1):77-84.

Fanta, G. F., R. C. Burr, W. M. Doane, and C. R. Russell. 1971. Influence of starch-granule swelling on graft-copolymer composition. A comparison of monomers. Journal of Applied Polymer Science 15(11):2651-60.

Günes, T. 2007. Effect of polymer on seedlings survival and growth of transplanted tomato under water stress. Asian Journal of Chemistry 19 (4):3208-14.

Hadi, M. R., R. Taheri, and M. S. Sharif. 2007. Study effects of salinity on the seed germination of Seidlitzia rosmarinus. Pajouhesh Va Sazandeg 67:151-7.

Hadi, M. R. 2009. Biotechnological potentials of Seidlitzia rosmarinus: A mini review. African Journal of Biotechnology 8(11):2429-31.

Han, Y. G., P. L. Yang, Y. P. Luo, S. M. Ren, L. X. Zhang, and L. Xu. 2010. Porosity change model for watered super absorbent polymer-treated soil. Environmental Earth Sciences 61(6):1197-205.

Han, Y. G., Y. P. Yang, and L. Xu. 2005. Experimental studies on increase of yield and soil moisture of fruit tree by using super absorbent polymers. Scientia Agricultura Sinica 38:2486-91. 
Hedge, I. C., H. Akhani, H. Freitag, G. Kother-Heinrich, D. Podlech, S. Rilke, and P. Uotila. 1997. Chenopodiaceae flora Iranica, no. 172. Akad. Druck-Und Verlagsanstalt, Graz 371.

Huttermann, A., L. J. B. Orikiriza, and H. Agaba. 2009. Application of super absorbent polymers for improving the ecological chemistry of degraded or polluted lands. Clean - Soil, Air, Water 37(7):517-26.

Huttermann, A., M. Zommorodi, and K. Reise. 1999. Addition of hydrogels to soil for prolonging the survival of Pinus halepensis seedlings subjected to drought. Soil Tillage Research 50(3-4):295-304.

Jafari, M., and F. Sarmadian. 2003. Fundamental of soil science and soil taxonomy. Iran: University of Tehran Press.

Jafari, M., M. A. Zare Chahouki, A. Tavili, and H. Azarnivand. 2003. Soil-vegetation relationships in Hoz-e-Soltan Region of Qom Province, Iran. Pakistan Journal of Nutrition 2(6):329-34.

Jafari, M., A. Tavili, F. Panahi, E. Zandi Esfahan, and M. Ghorbani. 2018. Reclamation of arid lands. Cham, Switzerland: Springer.

Johnson, M. S. 1984. Effect of soluble salts on water absorption by gel-forming soil conditioners. Journal of the Science of Food and Agriculture 35(10):1063-6.

Koocheki, A., and M. N. Mahallati. 1994. Feed value of some halophytic range plants of arid regions of Iran. The Netherlands: Kluwer Academic Publishers.

Kramer, P. J., and J. S. Boyer. 2015. Water relations of plants and soils. San Diego: Academic.

Kumar, R. 2015. Evaluation of hydrogel on the performance of Rabi maize. Ph.D. diss., Department of Agronomy, BAU, Sabour.

Kurkova, E. B., L. G. Kalinkina, O. K. Baburina, N. A. Myasoedov, and T. G. Naumova. 2002. Responses of Seidlitzia rosmarinus to salt stress. Biology Bulletin of the Russian Academy of Sciences Abbreviation 29(3):221-9.

Lee, S. S., S. X. Chang, Y. Y. Chang, and Y. S. Ok. 2013. Commercial versus synthesized polymers for soil erosion control and growth of Chinese cabbage. SpringerPlus 2(1):534.

Li, X., J. Z. He, J. M. Hughes, Y. R. Liu, and Y. M. Zheng. 2014. Effects of super-absorbent polymers on a soil-wheat (Triticum aestivum L.) system in the field. Applied Soil Ecology 73:58-63.

Liao, R., P. Yang, W. Wu, and S. Ren. 2016. An inverse method to estimate the root water uptake source-sink term in soil water transport equation under the effect of superabsorbent polymer. Plos One 11(8):e0159936.

Liu, Z., Y. Miao, Z. Wang, and G. Yin. 2009. Synthesis and characterization of a novel superabsorbent based on chemically modified pulverized wheat straw and acrylic acid. Carbohydrate Polymers 77(1):131-5.

Moghimi, J. 2005. The most important plants for reclamation of Iranian rangelands. Tehran: Arvan Press.

Montesano, F. F., A. Parente, P. Santamaria, A. Sannino, and F. Serio. 2015. Biodegradable superabsorbent hydrogel increases water retention properties of growing media and plant growth. Agriculture and Agricultural Science Procedia 4:451-8.

Mwangi, E., and S. Dohrn. 2008. Securing access to drylands resources for multiple users in Africa: A review of recent research. Land Use Policy 25(2):240-8.

Nassef, M., S. Anderson, and C. Hesse. 2009. Pastoralism and climate change: Enabling adaptive capacity. Humanitarian policy group. London: Overseas Development Institute.

Ni, B., M. Z. Liu, S. Y. Lu, L. Xie, X. Zhang, and Y. F. Wang. 2010. Novel slow-release multielement compound fertilizer with hydroscopicity and moisture preservation. Industrial \& Engineering Chemistry Research 49(10):4546-52.

Orikiriza, L. J. B., H. Agaba, M. Tweheyo, G. Eilu, J. D. Kabasa, and A. Huttermann. 2009. Amending soils with hydrogels increases the biomass of nine tree species under non-water stress conditions. Clean - Soil, Air, Water 37(8):615-20.

Oscroft, D. G., K. M. Little, and P. W. M. Vireo. 2000. The effect of a soil-amended hydrogel on the establishment of Pinus elliottii $\times$ caribaea rooted cuttings on the Zululand Coastal Sands (ICFR Bulletin Series). 19. ICFR, 8.

Peng, N., Y. Wang, Q. Ye, L. Liang, Y. An, Q. Li, and C. Chang. 2016. Biocompatible cellulosebased superabsorbent hydrogels with antimicrobial activity. Carbohydrate Polymers 137:59-64. 
Qiao, D., H. Liu, L. Yu, X. Bao, G. P. Simon, E. Petinakis, and L. Chen. 2016. Preparation and characterization of slow-release fertilizer encapsulated by starch-based superabsorbent polymer. Carbohydrate Polymers 147:146-54.

Ramos, M. C., and J. A. Martínez-Casasnovas. 2007. Soil loss and soil water content affected by land levelling in Penedès vineyards, NE Spain. CATENA 71(2):210-7.

Salinger, M. J., C. J. Stigter, and H. P. Das. 2000. Agro meteorological adaptation strategies to increasing climate variability and climate change. Agricultural and Forest Meteorology 103(1-2):167-84.

Sarah, P. 2006. Soil organic matter and land degradation in semi-arid area, Israel. Catena 67(1):50-5.

Schmidt, M., and O. Pearson. 2016. Pastoral livelihoods under pressure: Ecological, political and socioeconomic transitions in Afar (Ethiopia). Journal of Arid Environments 124:22-30.

Shahid, S. A., A. A. Qidwai, F. Anwar, I. Ullah, and U. Rashid. 2012. Improvement in the water retention characteristics of sandy loam soil using a newly synthesized poly (acrylamide-co-acrylic acid)/AlZnFe ${ }_{2} \mathrm{O}_{4}$ superabsorbent hydrogel nanocomposite material. Molecules 17(8):9397-412.

Sharma, S., A. Dua, and A. Malik. 2014. Polyaspartic acid based superabsorbent polymers. European Polymer Journal 59:363-76.

Tavili, A., S. H. Mahallati, M. A. Zare Chahouki, and S. Khalighi. 2010. Effects of superabsorbent A200 application on Haloxylon persicum establishment and decrease of vegetation development projects costs. The 6th International GIAN Symposium on Protection and Utilization of Ecosystems in Arid and Semi Arid Regions, Karaj, Iran, 2-6 October 2010.

Taylor, K. C., and R. G. Halfacre. 1986. The effect of hydrophilic polymer on media water retention and nutrient availability to Ligustrum lucidum. HortScience 21:1159-61.

Tilman, D., K. G. Cassman, P. A. Matson, R. Naylor, and S. Polasky. 2002. Agricultural sustainability and intensive production practices. Nature 418(6898):671-7.

Viero, P. W. M., K. E. A. Chiswell, and J. M. Theron. 2002. The effect of a soil amended hydrogel on the establishment of a eucalyptus grandis clone on a sandy clay loam soil in Zululand during winter. Southern Africa Forest Journal 193(1):65-75.

Viero, P. W. M., K. M. Little, and D. G. Oscroft. 2000. The effect of a soil amended hydrogel on the establishment of a Eucalyptus grandis $\mathrm{x}$ E. camaldulensis clone grown on the sandy soils of Zululand. Southern Africa Forest Journal 188(1):21-8.

Wang, G. J., M. Li, and X. F. Chen. 1998. Preparation and water-absorbent properties of a waterswellable rubber. Journal of Applied Polymer Science 68(8):1219-24.

Wang, F., X. Mu, R. Li, L. Fleskens, L. C. Stringer, and C. J. Ritsema. 2015. Co-evolution of soil and water conservation policy and human-environment linkages in the yellow river basin since 1949. Science of the Total Environment 508:166-77.

Watts, W. R. 1974. Leaf extension on Zea mays L. III. Field measurement of leaf extension in response to temperature and leaf water potential. Journal of Experimental Botany 25(6):1085-96.

Yang, P. L., C. Z. Wang, S. M. Ren, Y. K. Li, and T. W. Xu. 2003. Experimental studies of affections on the absorbable and holding characteristics of water-retaining agent in different solution environments and the approaches to increasing its field efficiency. Journal of Experimental Botany 31 (Oxford University Press, Oxford, England).

Yang, L., Y. Yang, Z. Chen, C. Guo, and S. Li. 2014. Influence of super absorbent polymer on soil water retention, seed germination and plant survival for rocky slopes eco-engineering. Ecological Engineering 62:27-32.

Zhang, H., Q. Luan, Q. Huang, H. Tang, F. Huang, W. Li, C. Wan, C. Liu, J. Xu, P. Guo, and Q. Zhou. 2017. A facile and efficient strategy for the fabrication of porous linseed gum/cellulose superabsorbent hydrogels for water conservation. Carbohydrate Polymers 157:1830-6.

Zohuriaan-Mehr, M. J., and K. Kabiri. 2008. Super absorbent polymer materials: A review. Iran Polymer Journal 17(6):451-77. 